Faculdade de Ciências Econômicas UFRGS
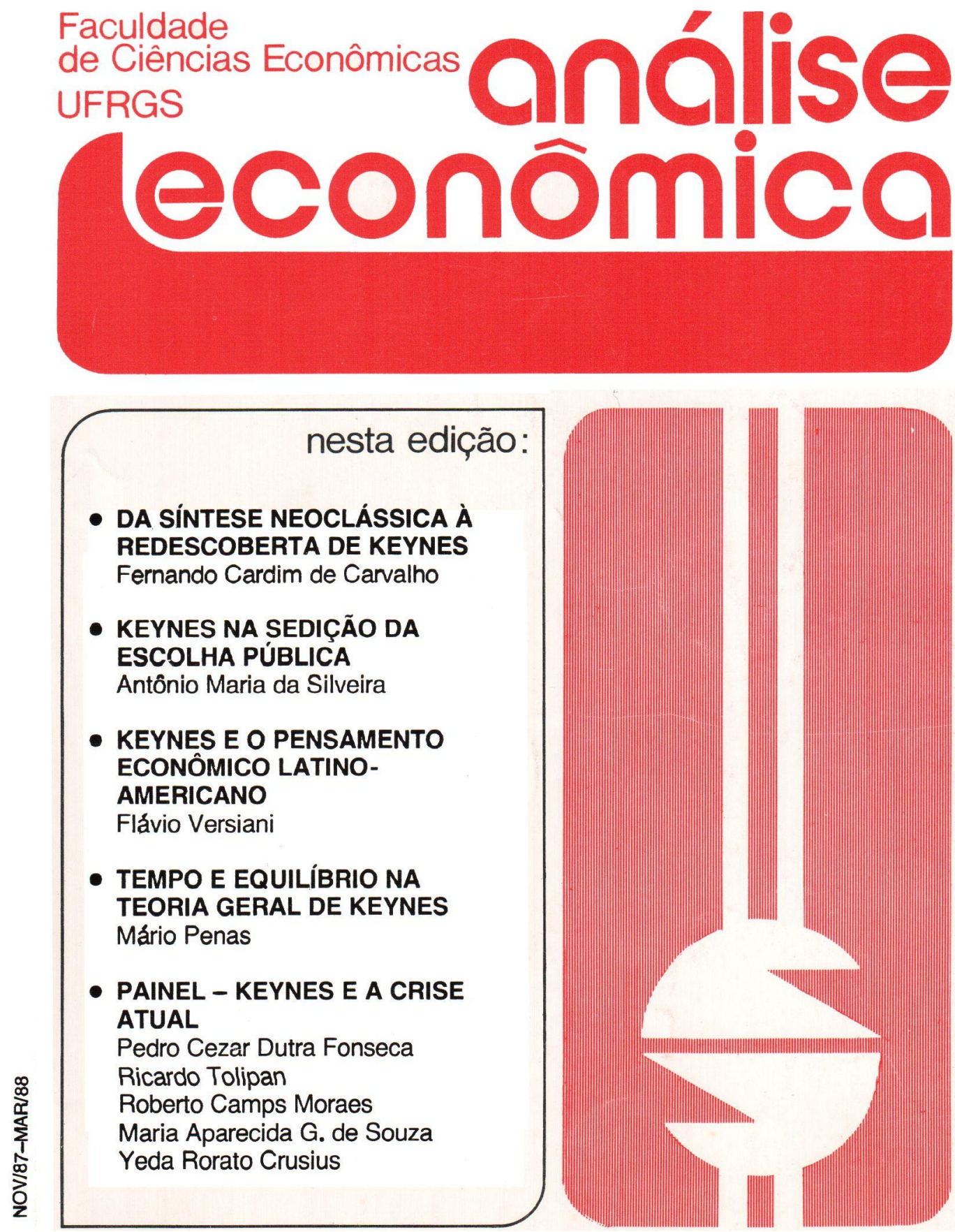
REITOR: Prof. Gerhard Jacob

DIRETOR DA FACULDADE DE CIÊNCIAS ECONÔMICAS:

Prof. Walter Meucci Nique

CHEFE DO DEPARTAMENTO DE CIÊNCIAS ECONÔMICAS:

Prof ${ }^{a}$. Otília Beatriz K. Carrion

CONSELHO EDITORIAL:

Prof. Pedro Cezar Dutra Fonseca (Presidente)

Prof. Achyles Barcelos da Costa

Prof. Carlos Augusto Crusius

Prof. Edgar Augusto Lanzer

Prof. Hernani Hickmann

Prof. Juvir Mattuella

Prof. João Rogério Sanson

Prof ${ }^{a}$ Maria Imilda da Costa e Silva

Prof. Nali de Jesus de Souza

Prof. Nuno Renan L de Figueiredo Pinto

Prof- Otilia Beatriz Kroeff Carrion

Prof ${ }^{a}$ Yeda Roratto Crusius

Prof. Paulo Alexandre Sphor

Prof. Roberto Camps Moraes

FUNDADOR:

Prof. Antonio Carlos Rosa

ANÁLISE ECONÔMICA publica dois números anuais nos meses de março e novembro. O preço da assinatura para 1988 é $\mathrm{Cz} \$ 500,00$, a ser pago através de cheque nominal para "Faculdade de Ciências Econômicas - UFRGS". Aceita-se permuta com revistas congêneres. Aceitam-se, também, livros para elaboração de resenhas ou recensões.

Toda correspondência, material para publicação, assinaturas e permutas devem ser dirigidas a:

Prof. PEDRO CEZAR DUTRA FONSECA

Revista Análise Econômica

Av. João Pessoa, $52-3^{\circ}$ andar

90.000 - Porto Alegre (RS) - Brasil 


\title{
PAINEL-KEYNES E A CRISE ATUAL
}

Prof. Pedro Cezar Dutra Fonseca*

\author{
Pedro Cezar Dutra Fonseca \\ Ricardo Tolipan \\ Roberto Camps Moraes \\ Maria Aparecida G. de Souza \\ Yeda Rorato Crusius
}

Ao lado dos trabalhos e exposições apresentados enfocando diversos aspectos da obra de Keynes, pretendemos com este painel pensar e discutir suas contribuições frente à crise contemporânea. Este é o momento de nosso ciclo "Keynes em Debate" que'nos impõe uma tarefa especial, com vistas a um entrosamento direto das concepções teóricas e as políticas econômicas keynesianas corn os impasses em que nos encontramos.

Contamos, para tanto, com as presenças de Ricardo Tolipan, da UFRJ e da ANPEC; de dois professores do Departamento de Ciências Econômicas e do Curso de Pós-Graduação em Economia da UFRGS, da área de macroeconomia, Roberto Camps Moraes e Yeda Rorato Crusius; e de Maria Aparecida Grendene de Souza, professora da UNISINOS e Presidente do Conselho Regional de Economia - 4a Região.

Diante do tema proposto, e principalmente por sua abrangência, permitimos aos nossos convidados interpretá-lo da forma mais ampla possivel, delimitando-o como os aprouver. Assim, por crise atual podese enfocar tanto seu caráter internacional como, especificamente e em particular, a crise da economia brasileira. Além disso, é importante notar que, sob este título, há também a liberdade de concebê-la como a crise da própria teoria econômica, tão importante e instigante para o debate quanto os dois aspectos anteriores. Todas estas concepçōes de crise estão, evidentemente, relacionadas; não obstante, cada painelista poderá enfatizar determinado aspecto que considere mais relevante ou oportuno para este painel, sem a pretensão de abranger todas as óticas.

Temos certeza que, qualquer que seja o ângulo escolhido, a fundamental e polêmica presença de Keynes estará presente, incitando-nos ao debate, como é praxe nestes cinqüenta anos desde a publicação da "Teoria Geral".

* Do Departamento de Ciências Econômicas e do Curso de Pós-Graduação em Economia da UFRGS.

\begin{tabular}{|l|l|l|l|l|}
\hline ANÁLISE ECONÔMICA & ANO 6 & № 9 & NOV/87-MAR/88 & p.67-78 \\
\hline
\end{tabular}


Ricardo Tolipan* - A idéia de crise, a entendo, numa concepção inicial, como a crise da teoria. $O$ fato de estarmos vivendo um momento de crise da teoria abre espaço para uma verdadeira teoria derivada diretamente de Keynes.

O título do ciclo de palestras que estamos participando, "Keynes em Debate", é um título, não sei se consciente ou inconscientemente, irônico, do meu ponto de vista, devido ao fato de Keynes estar em debate há mais de cinqüenta anos. Este debate, se deixou alguma coisa de fora, deixou Keynes, precisamente.

Como provocação inicial ao debate, se tivesse que escolher uma frase espetacular, seria: "Um debate sobre Keynes moderno destes últimos cinqüenta anos". No meu entender, é um debate fundamental Pré-Keynesiano. De fato, com honrosas exceções, a teoria neo-keynesiana, ou pós-keynesiana, é uma teoria dominada pela capacidade camoleônica do discurso neoclássico de adaptar-se às situaçōes de adversidade: sem dúvida, a obra de Keynes, "Teoria Geral", é uma pedra no meio do caminho neoclássico, parafraseando o poeta morto, Drummond, mas não levou uma para ser retirada. A síntese neoclássica começa com Hicks em 1937, quase completa. Conclui-se com Patinking, dez, quinze anos depois, mas a ele deve-se apenas a formalização final de um processo de recuperação do incômodo keynesiano de um ponto de vista ortodoxo.

Se quiséssemos sintetizar a questão ortodoxa de alguma maneira, diríamos que ela vê o capitalisr, o menos apoiado em instituições sócio-políticas-econômicas, mas fundamentalmente apoiado, em mercados capazes de ajustes quase automáticos entre os diversos planos de gastos, necessidades e rentabilidade entre firmas e consumidores que constituíram seus elementos. Esses mercados seriam definidos por produtos totalmente interdependentes e um equilíbrio geral destes mercados seria possivel - esses mercados são todos entendidos como entidades que estão funcionando, seguindo, mais ou menos, uma lógica que funciona simetricamente entre consumidores e produtores, sendo este modelo ou cenário a base do raciocínio ortodoxo.

No meu entender, como no de outras tantas pessoas - os quais Keynes chama de heréticas e entre elas incluia-se - o projetc de Keynes contraria fundamentalmente esse cenário. $O$ que se prega na "Teoria Geral" - e com isso estou de acordo - é uma idéia de interferência geral entre todos os mercados com configuração e interprestação de base que é o capitalismo. Penso ser uma postura essencial perceber estes mecanismos fundamentais de uma forma diferente da

* Da UFRJ, Secretårio Executivo da ANPEC. 
visão ortodoxa. Para Keynes deriva-se uma imagem de mercado que não contrapōe simetricamente produtores e consumidores, mas há uma simetria fundamental na constituição dos mercados capitalistas. Keynes entende que as curvas de demanda e oferta são, fundamentalmente, constituidas por um único destes dois elementos. As firmas, as empresas, na verdade, os consumidores, têm uma participação secundária na conformação da demanda e ofertas globais. Keynes, parece, também não acredita muito na uniformidade e interdependência dos diversos mercados. A minha sensação e a de muitos heréticos, penso eu, é de que Keynes dava uma certa primazia a um mercado especial que é o financeiro, mercado de constituição da moeda e da taxa de juros. Segundo uma lógica dos mercados de outros produtos, esse mercado presidia o espetáculo. De fato, numa interpretação nāo-ortodoxa, aparentemente Keynes pensava que a idéia de comportamento nacional estava na base da praxiologia ortodoxa-neoclássica, não explicando o funcionamento dos mercados.

Para Keynes, a idéia de incerteza fazia sem que qualquer produtor tivesse a crença, muito forte, em seu próprio cálculo microeconômico. Deste modo, os mercados funcionariam segundo um comportamento fortemente limitativo, sendo que algum mercado daria um sinal forte regularizando os comportamentos de mercado. Isto é, fundamentalmente, diferente da visão ou do cenário neoclássico/ortodoxo de interpretação do capitalismo. Este cenário é muito poderoso para que se possa criticar com meia dúzia de palavras, na verdade, ele foi muito bem construído do ponto de vista lógico e teórico. É o cenário que sofreu o choque keynesiano da presença da obra do autor, em 1936, absorvendo e adaptando-se ao seu discurso. Se olharmos os manuais de macroeconomia produzidos a partir de então, veremos que o ensino da macroeconomia estava dominado pelo debate iniciado pela consolidação da IS-LM. Todo projeto de pesquisa fundado na síntese neoclássica tem uma base microeconômica Walrasiana. Recentemente, sofreu uma nova crítica interna derivada da chamada "teoria do desequilíbrio", desembocando na crítica da base estritamente Walrasiana do momento de equilibrio geral. Porém, não se sai deste cenário básico de contraposição simétrica entre firmas e consumidores, comportamentos racionais, idéias de interdependência geral. Temos que se pode adotar um ponto de equilíbrio no funcionamento geral da economia, dando a idéia fundamental de que a economia capitalista é auto-regulável. Uma idéia contra qual, penso eu, Keynes contrapõe-se. Merece destaque, na obra de Keynes, duas grandes intuições: uma é de que o capitalismo não funciona desta maneira, ao contrário, os mercados no capitalismo são mercados não-equivalentes, isto é, há um mercado que 
é mais igual, mais equivalente que alguns outros, que é o mercado financeiro.

A idéia poderosa é que, através do estudo da moeda e das leis de funcionamento de constituição do que vem a ser moeda no capitalismo, podemos chegar a uma conclusão fundamental do seu mecanismo de funcionamento. As vantagens que temos hoje, chamados aqui "crise do pensamento econômico atual", é que o modelo de raciocínio neoclássico ou ortodoxo, apesar de ser dominante do ponto de vista político, institucional, social e mesmo a nivel teórico e lógico, não é mais a armadura absolutamente imbativel de vinte anos atrás. Ocorreram rachaduras importantes. Algumas críticas internas mostra-nos que esse modelo, hoje, funciona ou é capaz de perceber o capitalismo segundo exigência de caráter lógico excessivamente restritos, de modo que o seu funcionamento e a sua pretensão à generalização estão, hoje, abalados.

Penso, então, que está aberto o caminho para reconstituição de uma percepção do que é capitalismo. Particularmente, não tenho dúvidas, ele não será, jamais, keynesiano; porém Keynes terá dado contribuições decisivas para uma visão moderna de capitalismo.

Roberto Campos Moraes ${ }^{\star}$ - Dentro do tema proposto, "Keynes e a Crise Atual", eu interpreto o termo "crise atual" como se referindo a uma crise das políticas keynesianas. No plano teórico, Hicks, em seu livro "A Crise da Teoria Keynesiana", fez uma revisão do modelo keynesiano e de sua própria contribuição (a versão IS-LM) colocando o assunto nos seus devidos termos. Ele esclarece que a simplificação dessas curvas deve ser encarada como uma mera instrumentação analítica para fins didáticos de uma parte da teoria de Keynes, a qual ele considerava como nuclear. O próprio Keynes concordou com a sua interpretação por escrito. A força desta simplificação é atestada pela sua perenidade e pela sua capacidade de incorporar até a crítica monetarista. Embora muitos encarem a "crise atual" como crise da "economia keynesiana" no sentido de que a "crise" é provocada pelo "abastardamento" metodológico (devido à versão IS-LM) da teoria keynesiana, o que tornaria a sua versão vulgar incapaz de capturar as complexidades da realidade econômica, e que teriam sido abordadas adequadamente pelo Keynes genuíno, eu creio que a "crise" situa-se em um nivel mais mundano.

Qual seria, então, a base desta "crise" das teorias keynesianas? A meu ver, essa crise deriva-se basicamente de fatores institucionais que alteraram o comportamento das economias capitalistas na década

\footnotetext{
* Do Departamento de Ciências Económicas e do Pós-Graduação em Economia da UFRGS.
} 
de 70. Ao alterarem o comportamento das economias, eles determinaram que a teoria macroeconômica inspirada em Keynes, a qual interpretava e modelava o comportamento dos agentes econômicos da década de 30 , deixasse de se conformar à realidade mais recente. Eu não diria, de forma alguma, que o keynesianismo como teoria esteja morto hoje em dia. Penso, isto sim, que as aludidas mudanças de comportamento conduziram a uma perda de influência intelectual de uma teoria que fundamentava políticas que passaram a não mais funcionar.

Quando a realidade muda a teoria que a pretende explicar também deve mudar, pelo menos em algumas de suas hipóteses e implicaçōes. Para se ter idéia de algumas mudanças na realidade econômica desde a época de Keynes, basta lembrar que, na década de 30, para se saber a taxa de inflação do mês passado seria necessário recorrer a um instituto de pesquisa econômica, isto nos centros mais desenvolvidos da Europa e EUA. Quer dizer, conhecer-se a variação de preços ao consumidor era uma tarefa complexa que implicava custos, pesquisa individual, etc. Hoje em dia somos bombardeados, diariamente, pelos meios de comunicação que nos dão os resultados imediatos das pesquisas realizadas por vários órgãos como DIEESE, IEPE, IBGE, FGV, etc. Penso que isto deve fazer alguma diferença no comportamento dos agentes econômicos. Uma implicação fundamental desta instantaneidade de informações está na percepção que o agente econômico tem da variação de seu poder aquisitivo. Isto obviamente afeta o chamado fenômeno da "ilusão monetária", o qual Keynes incorporou corretamente na lista de suas explicações para a existência de "equilibrios" com desemprego. Outras hipóteses desta lista, como o papel dos salários relativos na formação das reivindicações salariais, são complementares dentro do pensamento de Keynes. Aliás, no meu entender, Keynes não teve a pretensão de dar uma única explicação, mas sim de sugerir várias hipóteses complementares; e nesta atitude reside a sua ambigüidade, imprecisão e riqueza teórica.

Uma outra hipótese importante em Keynes é a rigidez para baixo de preços e salários que é acompanhada de uma flexibilidade, via diferentes velocidades de aumento, do salário real. Esta flexibilidade do salário real permite a existência de uma relação inversa, no curto prazo, entre $Q$ nivel de emprego e o salário real, uma relação básica no modelo keynesiano "bastardo". Assim, a estratégia keynesiana típica de saída da recessão envolve uma politica de expansão da demanda agregada associada a uma conseqüente queda no salário real. Se existe capacidade ociosa, então, não há explosão inflacionária, apenas uma variação "pequena" e suficiente para a reativação econômica. 
Sob este ponto de vista, a "crise atual" que existe consiste na perda deste "espaço keynesiano" de política econômica. Atualmente, devido a fatores institucionais, não é tão fácil provocar quedas "imperceptiveis" no salário real capazes de reativar o emprego. Devido à disponibilidade de informações rápidas e de baixo custo, e devido à indexação informal e/ou formal das economias, que emergiram em função do convivio com taxas crescentes de inflação, o salário real passou a exibir um grau de rigidez bem maior. Esta rigidez do salário real torna a economia capitalista menos suscetivel de ser manipulada por políticas "keynesianas". Ao mesmo tempo, o comportamento da economia passa a conformar-se a uma teoria que propõe ser impossivel manipular o nivel de emprego nessa economia. Penso que a isto se deve a dominância que hoje se verifica na teoria macroeconômica das proposições monetaristas ou "clássicas", no sentido de Keynes.

Por outro lado, a "crise" das políticas keynesianas conduziu a um esforço de revisão teórica no campo keynesiano que gerou uma série de reinterpretações de Keynes, processo este já ocorrido nos países desenvolvidos. O que se faz aqui, hoje em dia, não reflete o estado de espírito do mundo acadêmico dos países desenvolvidos. Esta valorização do Keynes "genuíno" é um fenômeno mais brasileiro e de alguns poucos paises europeus talvez, que reflete uma certa defasagem na pesquisa teórica e uma predileção terceiromundista pela heterodoxia econômica. Nos EUA, por exemplo, Keynes, para o saber convencional acadêmico, está já há algum tempo superado.

Eu gostaria de contrastar o novo paradigma da macroeconomia ortodoxa com o keynesiano. Após a incorporação da crítica monetarista ao paradigma teórico dominante, o conceito de "equilíbrio macroeconômico" exige que, além da condição keynesiana de curto prazo "poupança planejada = investimento planejado", as expectativas dos agentes econômicos estejam ajustadas, o que só se verifica quando o produto efetivo coincide com o produto potencial da economia. Numa versão mais "monetarista", isto ocorre quando a taxa "natural" de desemprego vigora. Em termos do ensino de macroeconomia, se pegarmos um livro-texto atual e o compararmos com um de dez anos atrás, veremos que os efeitos de medidas de política econômica, que há dez anos atrás, eram tidos como permanentes no horizonte relevante, hoje o são apenas temporários e parte de uma trajetória que conduz a economia a um novo equilibrio com propriedades "monetaristas". Por exemplo, este equilibrio pode ser compativel com qualquer taxa de inflação, desde que ela seja "inercial" e perfeitamente antecipada por todos os agentes econômicos e a taxa "natural" de desemprego prevaleça. Há dez anos atrás, bastaria que a taxa de inflação estivesse 
associada a uma taxa de desemprego na vizinhança da Curva de Philips, negativamente inclinada, para que o equilibrio fosse genuino.

Apesar da incorporação da crítica monetarista, a estrutura analítica IS-LM e a análise de equilíbrio estático-comparativa a ela associada persistem. Pergunta-se, então, onde fica Keynes nesta história? Sabemos que Keynes foi o criador da macroeconomia moderna, de suas categorias analíticas fundamentais e de uma teoria de determinação da renda e do emprego no curto prazo que demonstrou ser válida por pelo menos 4 décadas, quando ela assumiu a posição de ortodoxia. Por estas razões ele merece a nossa homenagem. Mas, ignorar que as mudanças ocorridas nas economias industriais contemporâneas conduziram a uma obsolescência das politicas econômicas inspiradas nessa teoria seria desrespeitar o seu legado, no qual se inclui uma atitude de permanente inquietude intelectual e insatisfação com as "verdades" estabelecidas.

Finalizando, dentro das reinterpretações teóricas sugeridas para traduzir mais fielmente a teoria econômica de Keynes parece-me que a dos enfoques de desequilíbrio é a mais bem sucedida no que se refere às implicações lógicas do "verdadeiro" Keynes. Em particular, Patinkin (no capitulo XIII de seu livro clássico), Leijonhufvud e Clower são os que melhor capturam a metodologia keynesiana. Além dos enfoques de desequilibrio - dos quais já fui um entusiasta -, a corrente auto-denominada de "pós-keynesiana" realiza ótimas interpretações críticas dos escritos de Keynes e da própria realidade econômica. Também expóem competentemente o irrealismo dos modelos de equilíbrio geral. O problema com essas correntes intelectuais é que elas não se tem mostrado capazes de fornecer blocos consistentes para a formação de uma nova estrutura analitica alternativa que seja capaz de competir com a ortodoxia vigente.

Maria Aparecida Grendene de Souza* - Gostaria de dizer, inicialmente, que achei excelente o tema "Keynes e a Crise Atual" proposto para o painel, inclusive, permitindo-me a liberdade no sentido de expressar o que gosto em Keynes e o que dele aproveito. O que aproveito em Keynes, assim como aproveito, essencialmente, em Schumpeter, assim como em Marx, é a visão de economia proposta por eles. Acredito, realmente, que a visão de economia encontrada em Keynes é de grande valia para que se pense a crise atual. Dentro desta visão de economia proposta por Keynes, destacarei aqueles pontos que acredito serem alavancas, serem férteis para o estabelecimento da relação de sua teoria com a crise atual.

\footnotetext{
* Presidente do Conselho Regional de Economia - 4ª Região.
} 
O primeiro ponto importante, no meu entender, a destacar, é o fato de Keynes propor-nos uma reflexão sobre uma economia de futuro.

O capitalismo, de fato, é um sistema econômico - sempre - voltado para o futuro. Dentro dessa proposição de sistema econômico, como uma economia do futuro, encontramos, do meu ponto de vista, a questão básica em Keynes, que é de como conservar a riqueza e como transportá-la para o futuro. Relacionadas a essa questão, encontramos duas grandes vertentes dentro da obra de Keynes, dois pontos que me parecem essenciais, quando se pensa a crise atual. Um deles é a questão da incerteza, basicamente relacionada com a questão das expectativas. Essas expectativas, então, referidas à conservação da riqueza no futuro, e não, simplesmente, ligadas ao fato de que o futuro é incerto, uma vez que ele sempre será.

Uma outra dimensão fundamental é, exatamente, a contradição com relação à questão do equilíbrio, tal como vinha sendo (e ainda é) colocada dentro da vertente clássica ou neoclássica, em virtude de estarmos tratando do futuro, em Keynes, como um equilibrio ex-ante e não como um equilibrio tendencial. Isto me parece um grau essencial de liberdade quando pensamos economia.

Ainda dentro da proposta de economia de futuro encontramos um outro elemento básico - fazendo elo entre o presente e o futuro - que é a moeda. Quando relacionamos a questão da moeda à questão do futuro, a questão das expectativas e, até mesmo, o próprio equilibrio ex-ante, todas englobadas dentro da questão de futuro, temos, em Keynes, ao meu entender, o momento de ruptura da lógica da identidade. A moeda dentro da concepção keynesiana impossibilita e invalida a teoria clássica anterior a ele. Dentro da teoria keynesiana a moeda aparece caracterizando a economia capitalista como uma economia monetária, tardiamente, do meu ponto de vista, pois isto já tinha sido feito por Marx. Mas, de qualquer forma, a moeda cria hiato dentro da teoria, hiato este que resiste ao método e pensamento tradicional, não conseguindo ser absorvido dentro da sintese neoclássica. Efetivamente, esta trata de retirar essa contradição, esse hiato introduzido por Keynes, ao pensar o capitalismo na sua forma específica, que é exatamente na forma de uma economia monetária.

Um outro ponto a salientar em Keynes, quando considera economia capitalista como economia do futuro, é o fato de que a conservação da riqueza assume uma forma, também, diversa daquela que tínhamos dentro do pensamento clássico, ou seja: para Keynes, a forma básica da riqueza deixa de ser o lucro, tornando-se, principalmente, a rentabilidade. Através da questão da rentabilidade, nós temos a decisão de investir, relacionada com uma carteira de ativos, relacionada 
com uma composição de aplicaçōes. Essa transição na forma da riqueza apontada por Keynes é a grande fonte para se considerar o capital financeiro $e$, nesse sentido, relacionamos esta linha de pensamento com a linha anterior, ou seja, a da economia capitalista como uma economia do futuro. Quando colocamos esta ponte, o caminho para o capital financeiro está aberto - eu reforço essa minha consideração - à medida que o problema crucial levantado é de como a produção será financiada. Está aberta, pois, essa reflexão sobre a questão do capital financeiro.

Um terceiro elemento que considero essencial para ser repensado dentro da visão de 'Keynes e a crise atual' é que, para Keynes, a economia é, claramente, política. Não só política na sua decorrência mais direta, ou seja, em face à clara impossibilidade de auto-regulação deste sistema econômico, da conseqüente necessidade de intervenção e presença permanente do Estado. Mas também que, para Keynes, a economia sendo política, a negociação é elemento essencial para se estabelecerem e definirem-se parâmetros. $O$ que admite e postula Keynes é a assimetria dos agentes econômicos, ou, usando um termo "exógeno", a assimetria do poder de barganha: até certo ponto, o poder de barganha desses agentes e a necessidade de que, politicamente, então, seja conduzida uma negociação. Politicamente, sendo entendido aqui, portanto, também como intervenção do Estado como uma politica mais diluída que se processa entre os próprios agentes econômicos. Então, essa outra questão de que a economia é política pareceme ser um outro elemento a resgatar, contrapondo-se, exatamente, aos modelos clássicos de pensamento.

Gostaria, ainda, de fazer uma observação em relação ao limite que vejo nesta proposta de Keynes, em termos da própria natureza política da economia e em termos da própria concepção geral relacionando com o segundo elemento colocado por mim, que é ponte para a questão do capital financeiro. Parece-me que Keynes via essa política conduzida, basicamente, pela ótica do capital produtivo, ou seja, a sua concepção, apesar da abertura do capital financeiro, está muito mais relacionada com o setor produtivo.

De qualquer forma, retomaria a questão da abertura do capital financeiro, relacionando com o conceito específico de preferência pela liquidez em Keynes. Vemos que a preferência pela liquidez, quando exercida pelo setor financeiro, pelo setor bancário, especificamente, é um elemento chave na questão da crise. A preferência pela liquidez impedirá que o financiamento das atividades produtivas se dê dentro daqueles moldes que poderiam atenuar a crise, sendo favoráveis, conseqüentemente, ao que seria uma política de pleno emprego. 
Yeda Rorato Crusius* - A Crise da Prática: painéis como este exigem a colocação e discussão de pontos os mais controversos e provocativos possíveis, dada a duração e a intensidade da crise atual por que passa grande parte das nações do mundo. Uma provocação interessante, sem dúvida, foi a do Professor Ricardo, de uma universidade mantida pelo Governo. Ao declarar a distância que o separa do mundo keynesiano, deve reconhecer que deve seu emprego às idéias e à prática exaradas principalmente a partir da Teoria Geral.

Fugindo da desgastada pergunta: que crise é esta?, precisamos buscar no presente o que é Keynes. A crise que se prolonga afetando de modo diferenciado a países endividados e a países líderes, que respondem pela gerência das moedas-forte, corresponde a uma fase do específico ciclo internacional das décadas de 70 e 80 . Mais frágeis, os países endividados navegam nas águas turbulentas desse momento ciclico, arcando com a maior parte dos resultados do ajustamento às mudanças de valorização do capital internacional, próprias da estagflação.

Diz-se que se renovam as tentativas de redirecionamento da economia mundial à nova realidade produtiva através de movimentos como o do néoliberalismo; explica-se a persistência dos processos inflacionários por uma nova versão da teoria das expectativas racionais; ressurgem os apocalipticos anúncios de ser esta "a última crise do capitalismo". Enquanto isto, os paises socialistas se debatem nas mesmas águas do movimento cíclico internacional, e tentam saidas transformadoras que apontam para mecanismos tipicamente capitalistas de produção e distribuição de renda. Em qualquer dos casos, a preocupação acerca do domínio dos processos de formação do emprego é vital. Essa dinâmica, sem dúvida, deve ser buscada em Keynes. As circunstâncias mudaram desde 1936, inclusive porque as ações praticadas sob a égide keynesiana - que vêm sendo aplicadas desde o pós-guerra - reconstruiram e renovaram as circunstâncias sobre as quais se pretendeu atuar.

Os elementos que quero ressaltar, não para alimentar qualquer mito, e sim para reafirmar idéias totalmente atuais levantadas por Keynes tanto no campo da teoria quanto da prática, são de duas ordens: o primeiro é o processo de aprendizado expresso nos contratos indexados, fenômeno típico de comportamento face à incerteza como teorizada por Keynes; o segundo é o resultado do processo de concentração das decisões de produção e de distribuição, viabilizado pelas trocas internacionais (transformação de produto em moeda-forte=va-

* Do Departamento de Ciências Econômicas e do Pós-Graduação em Economia/UFRGS. 
lor) e materializado no problema do endividamento mundial, fenômeno de geração e simulação amplamente analisado por Keynes através do clássico HOW TO PAY THE WAR.

O primeiro elemento, o da proteção que partes aceitam firmar mutuamente nos contratos face à incerteza quanto ao futuro, tem enrigecido fortemente os preços relativos e, em decorrência, inviabilizado a prática eficiente de políticas tradicionais de cunho monetário-fiscal para repartir os prejuizos do ajustamento face a estrangulamentos. Neste ponto, não é a teoria de Keynes que entrou em crise: para ele, a existência de algum grau de ilusão monetária é que justificaria como eficiente e socialmente recomendável a ação através dessas políticas.

Os indices de preços como cláusula de correção automática dos contratos têm sido na prática o sinalizador para a minimização de perdas médias, e como tal aceitos como salvaguarda nos contratos. Além desta, a prática requereria o rearranjo das instituiçōes ou dos acordos entre agentes, com objetivos claramente desenhados. Em sistemas frágeis no campo como o nosso, é uma prática improvável. Esse é um dado maior do que o contido em modelos de estabilização tradicionais. A releitura de Keynes, entretanto, aponta para a presença farta desse elemento integrante de suas idéias e de suas propostas, reforçando o caráter de exigência no entendimento dos processos de acordo entre partes, à luz das tantas propostas elaboradas por ele EM CONSONÂNCIA COM AS CIRCUNSTÂNCIAS NAS QUAIS DEVEM SER CRIADAS E POSTAS EM AÇĀO. O respeito às circunstâncias e o entendimento competente das mesmas são a grande contribuição de Keynes em propostas de institucionalização eficiente das políticas econômicas sob condições de indexação generalizada.

Quanto ao segundo elemento, Keynes mostrou que (e porque) os paises perdedores não teriam condiçōes de honrar os tratados de paz firmados. Vivemos hoje uma situação semelhante: somos os perdedores do jogo do crescimento com endividamento, e a destruição causada pela guerra recessão não mais viabiliza o ajuste necessário quando da reversão da liquidez internacional. Por termos sido investidores, tornamo-nos poupadores líquidos - porém essa poupança não retorna às nossas fronteiras para recuperar a capacidade de investir e produzir. $O$ desequilíbrio financeiro é crescente, recursivo.

Não é possivel pagar por esta guerra nos termos em que os tratados pós-endividamento foram firmados. Não há mais quem discorde desse fato típico dos anos 80. As circunstâncias sob as quais foram firmados mudaram, inclusive devido ao seu cumprimento parcial: os mecanismos de informação instantânea; a concentração dos fluxos de 
comércio, dos poderes de firmar preços internacionais, do dominio tecnológico; a transmissão imediata das flutuações de um mercado para todos os demais via sistema financeiro; a falência do mecanismo equilibrador intemacional, materializado nas instituiçōes supranacionais de crédito; são elementos (circunstâncias) novos que deveriam orientar as negociaçöes internacionais.

Em respeito ao conhecimento que a história proporciona, esta fortemente influenciada pelas idéias de Keynes neste século, é preciso que se reafirme que, tanto na teoria que embasa as açóes atuais, quanto nas práticas realizadas e propostas, os agentes do jogo do presente parecem não ter aprendido o suficiente de suas liçōes. A releitura de Keynes é, por isto, oportuna e vital para o debate a respeito da natureza da crise atual (iliquidez produtiva vs liquidez financeira), para que se embase com competência o rumo das propostas para sair dela. 